feeding imparted by a competent instructor. If such a chair were founded in our schools, for example, and a proper man found to fill it, we should realize that advance had been made in pediatrics.

The milk laboratories that have been established in many cities of the United States have done much to further the scientific feeding of infants. Those physicians who employ these laboratories most largely speak most strongly of the results obtained. My own experience in the use of milk modified according to my prescriptions, at the laboratories, has been so satisfactory that I can not praise this method too highly, and I should like to see a milk laboratory within the reach of all physicians who have infants to feed artificially. This, however, is impossible, and at best only a percentage of physicians can reach the laboratories with their prescriptions. But all physicians intending to devote themselves either to general medicine or to the special work of pediatrics should be permitted and encouraged to lay a solid foundation for this work while they are in the medical school. Therefore, I hope my appeal for special instruction in feeding of infants will not be made in vain.

\section{A NEW PROCTOSCOPE AND SIGMOIDOSCOPE} WILIJIAM M. BEACH, A.M., M.D.

Secretary of the American Proctologic Society. PITtshura, Pa.

Whis new instrument differs from the ordinary rectal tube in that it contains an illuminating attachment.

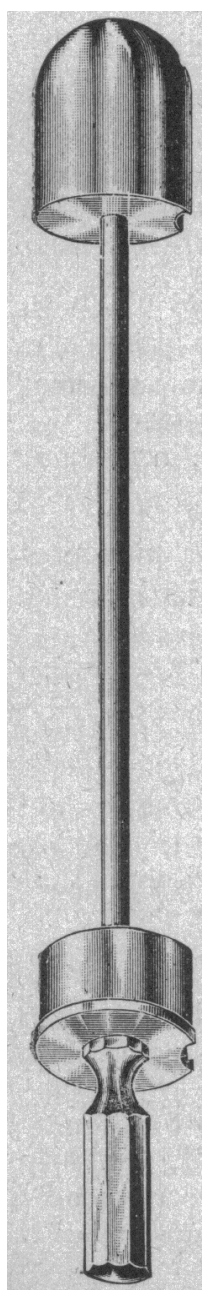

Figure 3.
The apparatus complete consists of the metallic tube, a metallic light-earrier, and a metal obturator.

1. The tube (Fig. 1) varies in length from an inch and a half (the anoscope) to eight inches. Though any length ean be made, the set usually contains three sizes: 1, the anoscope, one and a half inches long; 2 , the proctoscope, four inches long; and 3 , the sigmoidoscope, eight inches long. For diagnostic purposes, the caliber is seven-eighths of an inch; for operative purposes, as valvotomy, or removal of high-up polypus, the calibe $r$ is one and one-fifth inches, the same as in Martin's set. The handle is round and corrugated, and placed at the usual angle with the axis of the tube. In the wall of the tube on the side of the handle is an auxiliary tube projecting both within and without the speculum to receive the light-carrier (Fig. 2); it is so constructed that the diameter of the speculum is not appreciably enlarged or the caliber lessened. The auxiliary tube is lined with cement, holding in place a specially prepared glass which serves as a window at the distal end of the speculum. This glass can be subject to high temperature, so that the instrument can be sterilized with impunity. The glass window protects the incandescent light from any mucus, blood or other material that may be present in the ballooned rectum.

2. The light-carrier consists of a very light tube with a four-candle power incandescent lamp on the distal extremity, properly wired, and made to conform with the shape of the speculum, when placed in the auxiliary tube. The proximal extremity receives the wires from a dry-cell battery, the source of light. The handle is covered by rubber tubing to protect the wires, and is clamped to the upper border of the handle of the speculum.

3. The obturator (Fig. 3) consists of a metallic rod with enlarged distal and proximal portions to fit the speculum. The handle is an inch and a half long, which is held by the thumb during introduction of the instrument into the rectum. The two enlarged portions are fluted on one side to pass over the auxiliary tube containing the light-carrier.

On being called to the country to examine rectums, I have been hindered by reason of inadequate light, and in this instrument $I$ have secured a direet light and one more satisfactory than the reflected light heretufore used in my office and in hospital work.

The Electro-Surgical Instrument Co., of Rochester, New York, have been patient and careful in constructing the outfit to my satisfaction. The complete outfit, including battery, is put up in a neat $8 \times 10$ inch case, ready to carry as a satchel.

The advantages of this proctoscope are:

1. It is simple in construction.

2. 'There is no reflector to obstruct the view of the operator.

3. The light is direct and perfect.

4. The patient need not come to the office or hospital for examination.

5. It is practical and useful to the general practitioner.

6. It can be sterilized.

7. With ordinary care it will be serviceable for years.

8. With the patient in the Martin posture it can be introduced without pain.

Home Office Building. 